\title{
Fibroblast Growth Factor-23 Levels Are Associated with Vascular Calcifications in Peritoneal Dialysis Patients
}

\author{
Ebru Asicioglu Arzu Kahveci Hakkı Arikan Mehmet Koc Serhan Tuglular \\ Cetin Ishak Ozener \\ Department of Nephrology, Marmara University School of Medicine, Pendik, Turkey
}

\section{Key Words}

Fibroblast growth factor-23 - Vascular calcifications .

Peritoneal dialysis

\begin{abstract}
Background: The aim of the study was to assess the relationship between fibroblast growth factor-23 (FGF-23) and vascular calcifications (VC) in peritoneal dialysis (PD) patients. Methods: A cross-sectional study was performed in 55 PD patients who underwent pelvic X-ray to assess for VC. Patients with and without linear calcifications were recorded. Results: Fifteen patients (27.3\%) had linear calcifications on pelvic X-ray. FGF-23 levels were higher in patients with VC (299.5 (30.4-2,410.0) vs. $74.4(14.8-1,030) \mathrm{pg} / \mathrm{ml}, \mathrm{p}<0.01)$. Diabetic patients had lower FGF-23 values (43.2 (14.9-134.0) vs. $103.5(14.8-2,410) \mathrm{pg} / \mathrm{ml}, \mathrm{p}<0.01)$. Patients with residual renal function (RRF) had lower FGF-23 levels (70.6 (14.8-513) vs. $179.5(30.4-2,410) \mathrm{pg} / \mathrm{ml}, \mathrm{p}=0.06)$; however, this did not reach statistical significance. FGF-23 levels, age, creatinine, $\mathrm{Ca}$, dialysis duration and $\mathrm{HbA} 1 \mathrm{c}$ were positively correlated with VC, whereas RRF, Ca intake and ALP were negatively associated. Multivariate logistic analysis confirmed FGF-23 levels, age, dialysis duration and RRF to be associated with VC.
\end{abstract}

Conclusions: FGF-23 levels are associated with VC in PD patients. Further studies are needed to clarify whether it is simply a marker or a potential factor. It may prove to be an important therapeutic target for VC management.

(c) 2013 S. Karger AG, Basel

\section{Introduction}

Cardiovascular disease (CVD) is the leading cause of morbidity and mortality in end-stage renal disease (ESRD) patients. The cardiovascular mortality in this population is approximately 10 - to 20 -fold higher than in the general population, accounting for more than $50 \%$ of deaths $[1,2]$. Traditional risk factors alone do not explain the high incidence of atherosclerosis in this patient population.

Vascular calcifications (VC) are highly prevalent in ESRD patients and studies have shown that the presence and extent of calcifications are important risk factors for CVD and mortality [3,4]. The mechanism of VC has not been completely understood and is most likely multifactorial. Traditional and nontraditional risk factors have all been reported to be associated with VC [5].

\section{KARGER}

E-Mail karger@karger.com

www.karger.com/nec
(C) 2013 S. Karger AG, Basel

$1660-2110 / 13 / 1242-0089 \$ 38.00 / 0$
Ebru Asicioglu

Department of Nephrology

Marmara University School of Medicine

TR-34899 Istanbul (Turkey)

E-Mail easicioglu@yahoo.com 


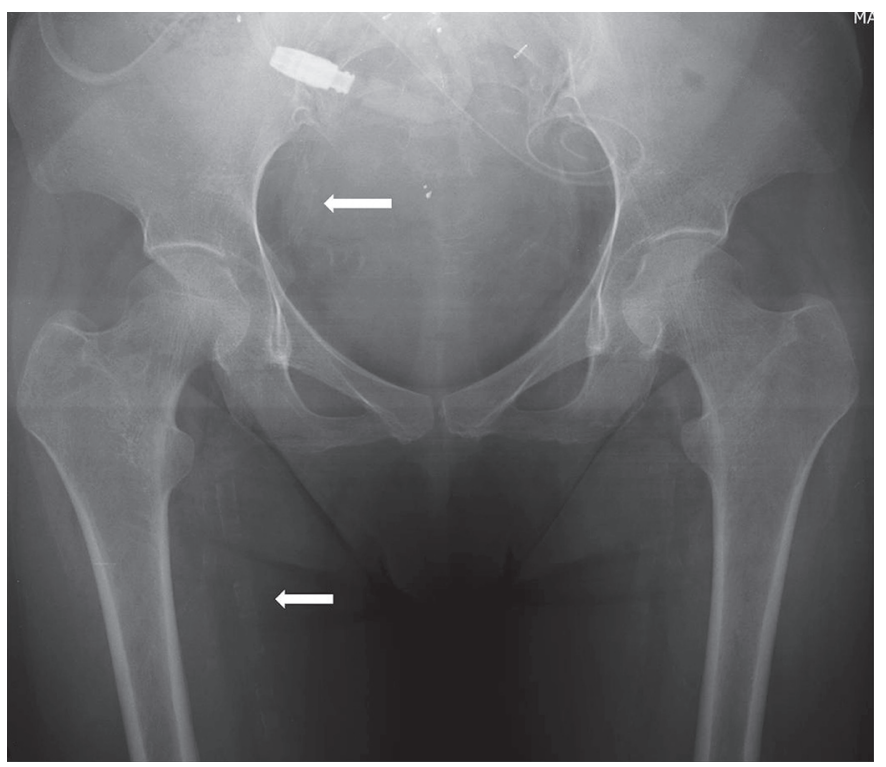

Fig. 1. Vascular calcifications detected by simple X-ray measurements. Arrows show calcified arteries.

Fibroblast growth factor-23 (FGF-23) is a recently identified hormone produced mainly by osteocytes that regulates phosphate metabolism. It induces phosphaturia by suppressing the $\mathrm{Na} / \mathrm{P}$ cotransporters in the proximal tubules and decreases calcitriol [6]. FGF-23 levels rise in parallel with the decline in renal function long before a significant increase in serum phosphate occurs [7].

Studies exploring the relationship between FGF-23 and VCs in mainly hemodialysis patients have reported conflicting results [8-11]. The aim of the present study was to determine whether FGF-23 levels are associated with VCs in peritoneal dialysis (PD) patients.

\section{Subjects and Methods}

\section{Patients}

The study was approved by the Marmara University Ethics Committee and carried out in accordance with the Helsinki declaration. All subjects gave informed consent. Overall, 78 patients were screened for inclusion in the study. Patients with CVD, malignancy, infectious or inflammatory disease, history of peritonitis within 3 months, parathyroidectomy, age less than 18 years and those who did not want to participate were excluded. In the end, $55 \mathrm{PD}$ patients and 40 age- and gender-matched healthy controls were included. Causes of ESRD were hypertension in 10 patients (18.2\%), chronic glomerulonephritis in 10 patients (18.2\%), diabetes in 9 patients $(16.4 \%)$, interstitial nephritis in 2 patients $(3.6 \%)$, vesicoureteral reflux in 1 patient $(1.8 \%)$, amyloidosis caused by familial Mediterranean fever in 1 patient (1.8\%), lupus nephritis in 1 patient (1.8\%) and uncertain in 21 patients (38.2\%). Medications were recorded at enrollment.

Laboratory Measurements

Blood was drawn after an overnight fasting. Plasma FGF-23 was measured by an enzyme-linked immunosorbent assay (ELISA; Immunotopics, Calif., USA) that detects the intact molecule.

\section{VC Measurement}

Anteroposterior X-ray of the pelvis was performed to assess for VC. One single radiologist evaluated all the films. Linear calcifications were defined as uniform railroad track-type opacities (fig. 1). Patchy calcifications were defined as discrete plaques with irregular and patchy distribution. The presence of linear calcifications with or without patchy calcifications was recorded. Isolated patchy calcifications were not considered. X-ray evaluation was performed within 2 weeks of enrollment. Patients with VC were classified as group 1, whereas those without VC were classified as group 2

\section{Statistical Analysis}

Statistical analysis was performed using SPSS for Windows, version 10.0, software (SPSS Inc., Chicago, Ill., USA). Student's $t$ test was used to compare means between groups and the $\chi^{2}$ test was used to compare proportions. For correlations between variables, the Pearson test was used for normally distributed data and the Spearman test for those with nonparametric distributions. We considered $\mathrm{p}<0.05$ as statistically significant.

\section{Results}

Fifty-five PD patients and 40 age- and gender-matched healthy controls were included. The mean dialysis duration was $49.6 \pm 40.6$ months. Nine patients $(16.4 \%)$ were diabetic. Forty patients $(72.7 \%)$ and 27 patients $(49.1 \%)$ were on antihypertensive and statin therapy, respectively. Fifty patients (90.9\%) were using calcium-based phosphorus binders, while 7 patients $(12.7 \%)$ were on sevelamer. Twenty-eight (51\%) and $40(72.7 \%)$ patients were on active vitamin $\mathrm{D}$ and erythropoietin, respectively.

Thirty-two patients $(58.2 \%)$ had residual renal function (RRF) while 23 patients (41.8\%) did not. Apart from lactate-based dialysis solutions, 22 patients (40\%) were using bicarbonate-based dialysis solutions. Forty-seven patients $(85.5 \%)$ used one icodextrin-based solution per day, while 18 patients (32.7\%) had one amino acid-based solution in their daily dwell. The mean Kt/V was $2.1 \pm 0.6$.

Demographic, clinical and laboratory parameters are shown in table 1. Vascular calcifications were present in 15 patients. Patients with diabetes (55.6 vs. $21.7 \%$, p < 0.05 ) and without RRF (56.5 vs. $6.3 \%, \mathrm{p}<0.05)$ had more VC. Patients with and without VC were further classified 
Table 1. Demographic, clinical and laboratory data of the study groups

\begin{tabular}{lccl}
\hline & $\begin{array}{c}\text { Patients } \\
(\mathrm{n}=55)\end{array}$ & $\begin{array}{c}\text { Controls } \\
(\mathrm{n}=40)\end{array}$ & $\mathrm{p}$ \\
\hline Age, years & $46.9 \pm 12.3$ & $44.8 \pm 6.9$ & n.s. \\
Male/female & $27 / 28$ & $20 / 20$ & n.s. \\
BMI & $26.8 \pm 4.7$ & $26.1 \pm 3.9$ & n.s. \\
SBP, mm Hg & $130.4 \pm 2.8$ & $119.2 \pm 1.5$ & n.s. \\
DBP, mm Hg & $79.4 \pm 1.5$ & $74.5 \pm 1.1$ & $<0.05$ \\
Glucose, mg/dl & $94.8 \pm 3.1$ & $94.4 \pm 1.7$ & n.s. \\
Total cholesterol, mg/dl & $195.8 \pm 39.2$ & $193.6 \pm 31.4$ & n.s. \\
LDL, mg/dl & $112.7 \pm 31.4$ & $115.9 \pm 25.2$ & n.s. \\
HDL, mg/dl & $46.3 \pm 15.1$ & $49.7 \pm 13.4$ & n.s. \\
Triglycerides, mg/dl & $186.5 \pm 113.3$ & $139.8 \pm 71.7$ & $<0.05$ \\
Hemoglobin, g/dl & $11.1 \pm 0.1$ & $13.9 \pm 0.2$ & $<0.01$ \\
Uric acid, mg/dl & $5.7 \pm 0.1$ & $4.6 \pm 0.2$ & $<0.01$ \\
CRP, mg/l & $9.1 \pm 1.2$ & $3.9 \pm 0.5$ & $<0.01$ \\
Albumin, g/dl & $4.0 \pm 0.1$ & $4.7 \pm 0.1$ & $<0.01$ \\
Ca, mg/dl & $9.1 \pm 0.1$ & $9.6 \pm 0.1$ & $<0.01$ \\
P, mg/dl & $5.2 \pm 0.2$ & $3.3 \pm 0.1$ & $<0.01$ \\
PTH, pg/ml & 360.0 & 41.2 & $<0.01$ \\
& $(6.6-2,500)$ & $(23.2-86.7)$ & \\
ALP, U/l & $339.6 \pm 334.7$ & $74.3 \pm 22.2$ & $<0.01$ \\
25-OH-D, $\mathrm{nmol} / \mathrm{l}$ & $48.7 \pm 34.6$ & $46.7 \pm 27.8$ & n.s. \\
FGF-23, pg/ml & 83.7 & 7.0 & $<0.01$ \\
& $(14.8-2,410.0)$ & $(3.7-35.3)$ & \\
\hline & & & \\
& & & \\
& & & \\
& & &
\end{tabular}

n.s. $=$ Nonsignificant.

as group 1 and group 2, respectively (table 2). FGF-23 levels were higher in patients as compared to the control group: $83.7(14.8-2,410.0)$ vs. $7.0(3.7-35.3) \mathrm{pg} / \mathrm{ml}, \mathrm{p}<$ 0.01 . FGF-23 levels were also higher in patients with VC as compared to those without: $299.5(30.4-2,410)$ vs. 74.4 $(14.8-1,030) \mathrm{pg} / \mathrm{ml}, \mathrm{p}<0.01$. Diabetic patients had lower FGF-23 values: 43.2 (14.9-134.0) vs. $103.5(14.8-2,410)$ $\mathrm{pg} / \mathrm{ml}, \mathrm{p}<0.01$. Even though patients with RRF had lower FGF-23 levels (70.6 (14.8-513) vs. 179.5 (30.4-2,410) $\mathrm{pg} / \mathrm{ml}, \mathrm{p}=0.06)$, this did not reach statistical significance. We further investigated the levels of FGF-23 in the dialysis fluid after a 4-hour dwell in 6 patients and the mean FGF-23 level was $90.7 \pm 46.2 \mathrm{pg} / \mathrm{ml}$.

We investigated the relationship between FGF-23 and markers of mineral metabolism. In univariate analysis, FGF-23 levels were positively correlated with Ca, P, PTH, the use of active vitamin D and VC. Multivariate analysis showed FGF-23 to be correlated with Ca, PTH and VC (table 3). We also calculated the urinary fractional excretion of phosphate (\%) in 25 patients with RRF. The mean urinary phosphate excretion rate (\%) was $48.3 \pm 18.0$ and it was positively correlated with FGF-23 ( $p<0.01$ ).
Table 2. Demographic, clinical and laboratory data of groups 1 and 2

\begin{tabular}{|c|c|c|c|}
\hline & $\begin{array}{l}\text { Group 1 } \\
(\mathrm{n}=15)\end{array}$ & $\begin{array}{l}\text { Group 2 } \\
(\mathrm{n}=40)\end{array}$ & $\mathrm{p}$ \\
\hline Age, years & $52.5 \pm 16.1$ & $45.8 \pm 12.3$ & n.s. \\
\hline Male/female & $9 / 6$ & $18 / 22$ & n.s. \\
\hline Dialysis duration, months & $80.5 \pm 46.4$ & $30.1 \pm 36.9$ & $<0.01$ \\
\hline $\mathrm{RRF}, \mathrm{ml} /$ day & $78.3 \pm 207.2$ & $694.9 \pm 702.3$ & $<0.01$ \\
\hline CAPD/APD & $7 / 8$ & $30 / 10$ & n.s. \\
\hline $\mathrm{Kt} / \mathrm{V}$ & $1.8 \pm 0.3$ & $2.2 \pm 0.7$ & n.s. \\
\hline BMI & $26.4 \pm 4.5$ & $27.0 \pm 4.8$ & n.s. \\
\hline SBP, mm Hg & $119.3 \pm 33.9$ & $131.4 \pm 21.6$ & n.s. \\
\hline $\mathrm{DBP}, \mathrm{mm} \mathrm{Hg}$ & $75.3 \pm 10.7$ & $81.4 \pm 10.9$ & n.s. \\
\hline Total cholesterol, mg/dl & $185.3 \pm 40.2$ & $199.3 \pm 38.2$ & n.s. \\
\hline $\mathrm{LDL}, \mathrm{mg} / \mathrm{dl}$ & $109.6 \pm 30.9$ & $113.8 \pm 31.5$ & n.s. \\
\hline $\mathrm{HDL}, \mathrm{mg} / \mathrm{dl}$ & $44.1 \pm 14.3$ & $46.7 \pm 15.6$ & n.s. \\
\hline Triglycerides, mg/dl & $185.3 \pm 40.2$ & $197.7 \pm 111.2$ & n.s. \\
\hline Hemoglobin, g/dl & $10.8 \pm 1.0$ & $11.1 \pm 1.1$ & n.s. \\
\hline $\mathrm{CRP}, \mathrm{mg} / \mathrm{l}$ & $9.3 \pm 7.9$ & $8.9 \pm 9.2$ & n.s. \\
\hline Glucose, mg/dl & $102.6 \pm 4.5$ & $92.5 \pm 4.0$ & $<0.01$ \\
\hline HbA1c, \% & $6.1 \pm 1.0$ & $5.6 \pm 1.2$ & $<0.05$ \\
\hline $\mathrm{Ca}, \mathrm{mg} / \mathrm{dl}$ & $9.6 \pm 0.8$ & $8.8 \pm 0.8$ & $<0.01$ \\
\hline Ca intake, g/day & $1.5 \pm 1.2$ & $2.4 \pm 1.3$ & $<0.05$ \\
\hline $\mathrm{P}, \mathrm{mg} / \mathrm{dl}$ & $5.4 \pm 1.3$ & $5.1 \pm 1.0$ & n.s. \\
\hline $\mathrm{PTH}, \mathrm{pg} / \mathrm{ml}$ & $\begin{array}{l}320.0 \\
(6.6-1,732.0)\end{array}$ & $\begin{array}{l}398.0 \\
(88.0-2,500.0)\end{array}$ & n.s. \\
\hline ALP, U/l & $213.8 \pm 86.7$ & $390.6 \pm 382.7$ & $<0.05$ \\
\hline b-ALP, U/l & $45.3 \pm 25.4$ & $35.0 \pm 25.8$ & n.s. \\
\hline $25-\mathrm{OH}-\mathrm{D}_{3}, \mathrm{nmol} / \mathrm{l}$ & $55.8 \pm 37.9$ & $45.8 \pm 34.5$ & n.s. \\
\hline FGF-23, pg/ml & $\begin{array}{l}299.5 \\
(30.4-2,410)\end{array}$ & $\begin{array}{l}74.4 \\
(14.8-1,030)\end{array}$ & $<0.01$ \\
\hline
\end{tabular}

n.s. = Nonsignificant; $\mathrm{b}-\mathrm{ALP}=$ bone specific alkaline phosphatase.

Table 3. Multivariate analysis results

\begin{tabular}{llll}
\hline & $\beta$ & $p$ & $95 \%$ CI \\
\hline Ca & 0.602 & $<0.01$ & $1.024-1.223$ \\
PTH & 0.491 & $<0.01$ & $1.001-1.016$ \\
Vascular calcification & 0.405 & $<0.01$ & $0.003-0.854$ \\
\hline
\end{tabular}

FGF-23, age, $\mathrm{Ca}$, dialysis duration and $\mathrm{HbA1c}$ were positively correlated with $\mathrm{VC}$, whereas RRF, Ca intake and ALP were negatively associated. Multivariate logistic analysis confirmed that FGF-23 levels, age, dialysis duration and RRF were independent predictors for VC. The results did not change when the treatments administered were included in the model (data not shown). 


\section{Discussion}

In our study, we assessed calcifications on pelvic radiographs in PD patients and found FGF-23 levels to be independently associated with VC. Jean et al. [12] have reported similar results in a study and further demonstrated that FGF-23 is one of the main factors associated with VC progression in long-hour dialysis patients. A recent article by Khan et al. [13] showed FGF-23 to be independently associated with the progression of CAC in new dialysis patients after a 1-year follow-up. Nasrallah et al. [8] have also reported a positive correlation between FGF-23 and aortic calcification assessed by noncontrast computed tomography. On the contrary, Inaba et al. [9] reported a negative correlation with peripheral calcifications. There has also been controversy regarding the relationship between FGF23 and coronary calcifications in several studies $[10,11]$. The difference in radiological techniques and the sites used to assess calcifications might explain some of these conflicting results.

The positive relationship between FGF-23 and VC is in contrast to animal studies in knock-out FGF-23 mice which consistently show extensive calcifications. Even though the exact mechanism is hard to deduce at this point, there may be several possible explanations. The rise in FGF-23 might be a result of excessive phosphate intake or hyperphosphatemia in dialysis patients. However, phosphate levels in our study as well as others failed to show any correlation with VC, suggesting an independent relationship [5, 8]. It is also possible that the rise in FGF-23 might reflect an unfavorable mineral metabolism predisposing to $\mathrm{VC}$, rather than being responsible for it per se. Interestingly, Coen et al. [14] reported an inverse relationship between FGF-23 and fetuin-A which decreased to borderline significance after correction for age and dialysis duration. However, further studies are needed to confirm a relationship between FGF-23 and bone inhibitors. Another key factor might be Klotho. FGF-23 exerts its effects through activation of the FGF-23 receptors in a Klothodependent manner. Like FGF-23, mice deficient in Klotho also have the phenotypic features of extensive VC [15]. In vitro studies have shown Klotho to have a direct effect on vascular smooth muscle cells by suppressing calcifications [16]. Recently, Lim et al. [17] have described endogenous Klotho expression in human arteries and human aortic smooth muscle cells for the first time. They further demonstrated that vascular Klotho deficiency potentiates the development of human artery calcifications and mediates resistance to FGF-23 [17]. Chronic kidney disease is a Klotho-deficient state $[16,17]$. In humans, the urinary ex- cretion of Klotho decreases in parallel to the drop in GFR; however, it is still secreted in the urine [16]. In our study, patients with RRF had significantly lower FGF-23 levels. Klotho secretion in the urine may in part explain this finding. It is also tempting to speculate that Klotho deficiency might be responsible for the rise in FGF-23 and thus be responsible for VC development in dialysis patients.

FGF-23 levels were lower in diabetic patients. Diabetes has recently been associated with lower FGF-23 in other studies $[18,19]$. Likewise, Nakano et al. [20] have recently shown higher FGF-23 to be associated with the absence of diabetes. The reason for this is unknown but may in part be explained by the high incidence of adynamic bone disease in this patient population. Interestingly, two recent studies have shown FGF-23 levels to be negatively correlated with the insulin resistive index, suggesting FGF-23 to have a potential role in the development of insulin resistance $[21,22]$. The relationship between FGF23 and insulin resistance may yet be another explanation for the lower levels observed in diabetics. The finding of lower FGF-23 levels in diabetic patients in this study and others is surprising, since diabetes predisposes to vascular calcifications. We speculate that factors other than FGF23 , which are specific to the diabetic milieu, are probably responsible for and affect calcification formation to a much greater degree in this patient population.

Even though patients with RRF had lower FGF-23 levels, this did not reach statistical significance probably due to the low number of patients in the study group. This finding is supported in a recent paper by Viaene et al. [23], who have recently shown an inverse relationship with FGF-23 and RRF, independent of dialysis vintage, dialysis creatinine clearance, dietary phosphate intake, vitamin $\mathrm{D}$ therapy, phosphorus and calcium levels. We were also able to demonstrate FGF-23 in the dialysate, showing that FGF-23 is indeed transported across the peritoneal membrane. This is in accordance with the article by Isakowa et al. [24], who have also reported FGF23 in the dialysis fluid in PD patients. How this affects PD patients in terms of vascular calcifications, cardiovascular and all-cause mortality remains to be seen.

Our study has several limitations. This is a cross-sectional study including a low number of PD patients. Furthermore, the mean time on dialysis treatment was about 4 years. Secondly, a majority of our patients were on phosphate binders and active vitamin D therapy. Thirdly, Klotho levels were not measured.

In our study, we used a simple pelvic X-ray to evaluate calcification in the iliac and femoral arteries. Evaluation of calcification by using plain radiography is less expen- 
sive, easily performed in clinical practice and exposes the patient to less radiation. Furthermore, the simple X-ray method has consistently been shown to be correlated with more sophisticated measurements obtained with electron beam tomography and cardiovascular mortality [25-27]. Similarly, London et al. [28] have also shown that calcification detected by plain pelvic X-ray is predictive of allcause and cardiovascular mortality in ESRD patients.

In conclusion, vascular calcifications are associated with FGF-23 levels in PD patients. Larger prospective studies are needed to confirm this relationship and to clarify whether FGF-23 is simply a marker or a potential factor for vascular calcifications. It remains to be seen if FGF-23 proves to be a therapeutic target for $\mathrm{VC}$ management.

\section{Disclosure Statement}

No conflicts of interest are reported.

\section{References}

1 Prasad N, Kumar S, Singh A, Sinha A, Chawla K, Gupta A, Sharma RK, Sinha N, Kapoor A: Carotid intimal thickness and flow-mediated dilatation in diabetic and nondiabetic continuous ambulatory peritoneal dialysis patients. Perit Dial Int 2009;29(suppl 2):S96-S101.

2 Stompór T, Kraśniak A, Sułowicz W, Dembińska-Kieć A, Janda K, Wójcik K, Tabor B, Kowalczyk-Michałek ME, Zdzienicka A, Janusz-Grzybowska E: Changes in common carotid artery intima-media thickness over 1 year in patients on peritoneal dialysis. Nephrol Dial Transplant 2005;20:404-412.

-3 Blacher J, Guerin AP, Pannier B, Marchais SJ, London GM: Arterial calcifications, arterial stiffness, and cardiovascular risk in end-stage renal disease. Hypertension 2001;38:938-942.

4 Bhan I, Thadhani R: Vascular calcification and ESRD: a hard target. Clin J Am Soc Nephrol 2009;4(suppl 1):S102-S105.

$>5$ Jean G, Bresson E, Terrat JC, Vanel T, Hurot JM, Lorriaux C, Mayor B, Chazot C: Peripheral vascular calcification in long-haemodialysis patients: associated factors and survival consequences. Nephrol Dial Transplant 2009; 24:948-955.

-6 Seiler S, Heine GH, Fliser D: Clinical relevance of FGF-23 in chronic kidney disease. Kidney Int Suppl 2009;114:S34-S42.

7 Alon US: Clinical practice. Fibroblast growth factor (FGF) 23: a new hormone. Eur J Pediatr 2011;170:545-554.

-8 Nasrallah MM, El-Shehaby AR, Salem MM, Osman NA, El Sheikh E, Sharaf El Din UA: Fibroblast growth factor-23 (FGF-23) is independently correlated to aortic calcification in haemodialysis patients. Nephrol Dial Transplant 2010;25:2679-2685.

-9 Inaba M, Okuno S, Imanishi Y, Yamada S, Shioi A, Yamakawa T, Ishimura E, Nishizawa Y: Role of fibroblast growth factor-23 in peripheral vascular calcification in non-diabetic and diabetic hemodialysis patients. Osteoporos Int 2006;17:1506-1513.

-10 Gutiérrez OM, Januzzi JL, Isakova T, Laliberte K, Smith K, Collerone G, Sarwar A, Hoffmann U, Coglianese E, Christenson R, Wang TJ, de Filippi C, Wolf M: Fibroblast growth factor 23 and left ventricular hypertrophy in chronic kidney disease. Circulation 2009;119:2545-2552.
11 Srivaths PR, Goldstein SL, Silverstein DM, Krishnamurthy R, Brewer ED: Elevated FGF 23 and phosphorus are associated with coronary calcification in hemodialysis patients. $\mathrm{Pe}$ diatr Nephrol 2011;26:945-951.

12 Jean G, Bresson E, Lorriaux C, Mayor B, Hurot JM, Deleaval P, Chazot C: Increased levels of serum parathyroid hormone and fibroblast growth factor-23 are the main factors associated with the progression of vascular calcification in long-hour hemodialysis patients. Nephron Clin Pract 2012;120:132-138.

13 Khan AM, Chirinos JA, Litt H, Yang W, Rosas SE: FGF-23 and the progression of coronary arterial calcification in patients new to dialysis. Clin J Am Soc Nephrol 2012;7:2017-2022.

14 Coen G, De Paolis P, Ballanti P, Pierantozzi A, Pisanò S, Sardella D, Mantella D, Pellegrino L, Silvestrini G, Iappelli M, Di Giulio S: Peripheral artery calcifications evaluated by histology correlate to those detected by CT: relationships with fetuin-A and FGF-23. J Nephrol 2011;24:313-321.

15 Razzaque MS: The FGF23-Klotho axis: endocrine regulation of phosphate homeostasis. Nat Rev Endocrinol 2009;5:611-619.

16 Hu MC, Shi M, Zhang J, Quiñones H, Griffith C, Kuro-o M, Moe OW: Klotho deficiency causes vascular calcification in chronic kidney disease. J Am Soc Nephrol 2011;22:124-136.

17 Lim K, Lu TS, Molostvov G, Lee C, Lam FT, Zehnder D, Hsiao LL: Vascular Klotho deficiency potentiates the development of human artery calcification and mediates resistance to fibroblast growth factor 23. Circulation 2012; 125:2243-2255.

18 Kojima F, Uchida K, Ogawa T, Tanaka Y, Nitta K: Plasma levels of fibroblast growth factor-23 and mineral metabolism in diabetic and non-diabetic patients on chronic hemodialysis. Int Urol Nephrol 2008;40:1067-1074.

19 Tanaka H, Hamano T, Fujii N, Tomida K, Matsui I, Mikami S, Nagasawa Y, Ito T, Moriyama T, Horio M, Imai E, Isaka Y, Rakugi $H$ : The impact of diabetes mellitus on vitamin $\mathrm{D}$ metabolism in predialysis patients. Bone 2009; 45:949-955.

20 Nakano C, Hamano T, Fujii N, Obi Y, Matsui I, Tomida K, Mikami S, Inoue K, Shimomura A, Nagasawa Y, Okada N, Tsubakihara Y,
Rakugi H, Isaka Y: Intact fibroblast growth factor 23 levels predict incident cardiovascular event before but not after the start of dialysis. Bone 2012;50:1266-1274.

21 Wojcik M, Janus D, Dolezal-Oltarzewska K, Drozdz D, Sztefko K, Starzyk JB: The association of FGF23 levels in obese adolescents with insulin sensitivity. J Pediatr Endocrinol Metab 2012;25:687-690.

22 Wojcik M, Dolezal-Oltarzewska K, Janus D, Drozdz D, Sztefko K, Starzyk JB: FGF23 contributes to insulin sensitivity in obese adolescents - preliminary results. Clin Endocrinol (Oxf) 2012;77:537-540.

23 Viaene L, Bammens B, Meijers BK, Vanrenterghem Y, Vanderschueren D, Evenepoel P: Residual renal function is an independent determinant of serum FGF-23 levels in dialysis patients. Nephrol Dial Transplant 2012;27: 2017-2022.

24 Isakova T, Xie H, Barchi-Chung A, Vargas G, Sowden N, Houston J, Wahl P, Lundquist A, Epstein M, Smith K, Contreras G, Ortega L, Lenz O, Briones P, Egbert P, Ikizler TA, Jueppner H, Wolf M: Fibroblast growth factor 23 in patients undergoing peritoneal dialysis. Clin J Am Soc Nephrol 2011;6:2688-2695.

$\checkmark 25$ Bellasi A, Ferramosca E, Muntner P, Ratti C, Wildman RP, Block GA, Raggi P: Correlation of simple imaging tests and coronary artery calcium measured by computed tomography in hemodialysis patients. Kidney Int 2006;70: 1623-1628.

26 Adragao T, Pires A, Lucas C, Birne R, Magalhaes L, Gonçalves M, Negrao AP: A simple vascular calcification score predicts cardiovascular risk in haemodialysis patients. Nephrol Dial Transplant 2004;19:1480-1488.

27 Adragão T, Pires A, Birne R, Curto JD, Lucas C, Gonçalves M, Negrao AP: A plain X-ray vascular calcification score is associated with arterial stiffness and mortality in dialysis patients. Nephrol Dial Transplant 2009;24:997-

28 London GM, Guérin AP, Marchais SJ, Métivier F, Pannier B, Adda $\mathrm{H}$ : Arterial media calcification in end stage renal disease: impact on all-cause mortality and cardiovascular mortality. Nephrol Dial Transplant 2003;18:17311740 . 